\title{
A pilot trial of dextromethorphan in amyotrophic lateral sclerosis
}

University Hospital, S-751 85 Uppsala, Sweden

Department of Neurology

H Askmark

S-M Aquilonius

P-G Gillberg

R Wuopio

Department of

Neurophysiology

L J Liedholm

E Stålberg

Correspondence to: Dr Askmark

Received 25 September 199 and in final revised form 19 May 1992

Accepted 26 May 1992

\author{
Håkan Askmark, Sten-Magnus Aquilonius, Per-Göran Gillberg, Lars Johan Liedholm, \\ Erik Stålberg, Rolf Wuopio
}

\begin{abstract}
Assuming the presence of glutamateinduced neurotoxicity in amyotrophic lateral sclerosis 14 patients were treated with dextromethorphan, an N-methyl-D-aspartate receptor antagonist. The patients were treated with $150 \mathrm{mg}$ dextromethorphan or placebo daily for 12 weeks in a double-blind crossover trial, with a wash out period of 4 weeks between the two treatment periods. Thereafter the surviving patients were treated with $300 \mathrm{mg}$ dextromethorphan daily for up to 6 months in an open trial. No positive effects on clinical or neurophysiological parameters (relative number of axons, and compound muscle action potentials in the abductor digiti minimi muscle) were observed either in the double-blind trial or in the open trial.
\end{abstract}

(F Neurol Neurosurg Psychiatry 1993;56:197-200)

In recent years neuroexcitotoxic mechanisms have been suggested as possible causes both for sporadic amyotrophic lateral sclerosis (ALS) ${ }^{1}$ and for the Guamanian form of ALS and Parkinson's dementia. ${ }^{2}$ The hypothesis by Plaitakis ${ }^{3}$ suggests that a generalised defect in excitatory amino acid metabolism in ALS may render a select group of neurons vulnerable to excitatory amino acid-induced neurotoxic damage because of their unique neuronal properties and the neurochemical character of their connections. Glutamate metabolism has been reported to be altered in ALS, ${ }^{45}$ it has been suggested ${ }^{6}$ that increased levels of synaptic glutamate could lead to pure excitation and degeneration of the motor neurons.
Plaitakis $e t a l,{ }^{1}$ who carried out a pilot trial of branched chain amino acids in ALS based on the theory that these amino acids might modify glutamate metabolism, have reported beneficial results from this treatment.

A subtype of glutamate receptor, the N-methyl-D-aspartate (NMDA) receptor, is thought to play a crucial role in glutamate-induced neuro-toxicity and it has been reported that specific antagonists to this receptor can exert protective effects against experimental neurodegeneration in which neuroexcitotoxic mechanisms have been implicated.

In view of the hypothesis and findings mentioned above it seemed reasonable to examine whether dextromethorphan, an NMDA receptor antagonist, ${ }^{89}$ has any beneficial effect in ALS.

\section{Material and methods \\ Patients}

Fourteen patients with ALS were included in the study, which was approved by the Ethics Committee of the Faculty of Medicine, University of Uppsala. The diagnosis was based on clinical findings and electro-myography according to the criteria developed by the World Federation of Neurology Subcommittee on Motor Neuron Disease. ${ }^{10}$ All patients except two were ambulatory. Six patients had swallowing difficulties and four patients had respiratory symptoms. For patient data see table.

Three patients died during the study because of respiratory complications due to their ALS. Patient 2 died after four months of participation in the study, in her second week on dextromethorphan medication. Patient 12 died after 10 weeks of treatment with placebo

Table 1 Characteristics of patients treated

\begin{tabular}{|c|c|c|c|c|c|c|c|c|}
\hline \multirow{2}{*}{$\begin{array}{l}\text { Patient } \\
\text { Number }\end{array}$} & \multirow[b]{2}{*}{ Sex } & \multirow[b]{2}{*}{ Age } & \multirow[b]{2}{*}{ Type } & \multirow{2}{*}{$\begin{array}{l}\text { Duration } \\
\text { (years) }\end{array}$} & \multicolumn{3}{|c|}{ Initial scores } & \multirow[b]{2}{*}{ Muscle function tested ${ }^{*}$} \\
\hline & & & & & Bulbar & Spinal & Norris & \\
\hline 1 & $\mathbf{M}$ & 50 & mainly upper motor neuron involvement & $2 \cdot 5$ & 7 & 98 & 42 & A left, $H$ right, $H$ left \\
\hline 2 & $\mathrm{~F}$ & 74 & bulbar symptoms predominant & $1 \cdot 5$ & 4 & 115 & 82 & A left, E left, $N$ right \\
\hline 3 & $\mathrm{~F}$ & 47 & mainly lower motor neuron involvement & $5 \cdot 0$ & 15 & 118 & 92 & $\mathrm{H}$ left, W right, W left \\
\hline 4 & $\mathrm{~F}$ & 79 & bulbar symptoms predominant & 0.5 & 5 & 112 & 87 & $H$ right, $H$ left, $W$ left \\
\hline 5 & $\mathbf{M}$ & 61 & mainly lower motor neuron involvement & $1 \cdot 5$ & 15 & 119 & 93 & $H$ right, $H$ left, $W$ left \\
\hline 6 & M & 59 & mainly lower motor neuron involvement & 1.5 & 15 & 86 & 80 & A right, $\mathrm{H}$ left, $\mathrm{N}$ \\
\hline 7 & $\mathrm{~F}$ & 80 & bulbar symptoms predominant & 0.5 & 4 & 126 & 87 & A right, $\mathrm{E}$ right, $\mathrm{H}$ left \\
\hline 8 & $\mathbf{M}$ & 58 & mainly lower motor neuron involvement & $3 \cdot 0$ & 15 & 62 & 60 & E left, $N$ left, W right \\
\hline 9 & $\mathrm{~F}$ & 47 & mainly lower motor neuron involvement & 1.5 & 15 & 128 & 97 & $\mathrm{~N}, \mathrm{~W}$ right, $\mathrm{W}$ left \\
\hline 10 & $\mathbf{F}$ & 64 & bulbar symptoms predominant & $1 \cdot 0$ & 11 & 117 & 84 & $N, W$ right, $W$ left \\
\hline 11 & $\mathbf{F}$ & 61 & mainly lower motor neuron involvement & $2 \cdot 0$ & 15 & 108 & 88 & E left, $H$ right, $W$ left \\
\hline 12 & $\mathbf{F}$ & 73 & bulbar symptoms predominant & $1 \cdot 0$ & 10 & 127 & 89 & E left, W right, W left \\
\hline 13 & $\mathrm{~F}$ & 47 & mainly lower motor neuron involvement & $0 \cdot 5$ & 13 & 116 & 92 & H right, $E$ left, $W$ left \\
\hline 14 & $\mathbf{M}$ & 69 & mainly lower motor neuron involvement & $1 \cdot 0$ & 15 & 114 & 73 & A left, $\mathrm{H}$ right, $\mathrm{N}$ \\
\hline
\end{tabular}

Maximal values 15130100

$\star A=$ abduction of the arm; $E=$ flexion of the elbow; $\mathrm{H}=$ flexion of the hip; $\mathrm{N}=$ flexion of the neck; $\mathrm{W}=$ extension of the wrist. 
and patient 14 died after taking part for four months in the trial in his second week on dextromethorphan. Dextromethorphan had to be withdrawn in one patient (11) after only three days of medication because of pronounced dizziness and nausea.

Drug trial

Dextromethorphan mixture $(3 \mathrm{mg} / \mathrm{ml})$ and tablets $(30 \mathrm{mg}$ ) were manufactured by Leo (Malmö, Sweden) who also prepared the placebo mixture. The effects of $150 \mathrm{mg}$ dextromethorphan daily for 12 weeks were studied in a double-blind cross over trial. The randomisation was organised by the hospital pharmacy. Half of the patients started with dextromethorphan and half with placebo. Each patient was given $150 \mathrm{mg}$ dextromethorphan mixture $(30+30+30+60 \mathrm{mg})$ per day for 12 weeks and then placebo for the same length of time or vice versa. There was a "wash-out" period of 4 weeks between the courses. The effects of $300 \mathrm{mg}$ dextromethorphan daily for 3-6 months were then studied in an open trial. Directly after termination of the double-blind study, the patients were given $300 \mathrm{mg}$ dextromethorphan daily as tablets or mixture (60 $+60+60+120 \mathrm{mg}$ ).

\section{Clinical parameters}

The neurological rating of the patients' status included the Norris score ${ }^{11}$ and a bulbar and spinal score according to Plaitakis, et al. ${ }^{1}$ The maximum values of the Norris and spinal score are 100 and 130 respectively and a score less than 60 and 90 respectively generally implies that the patient is severely disabled. The maximum value of the bulbar score is 15 and a bulbar score of 10 or less generally implies that the patients have pronounced problems both with speech and swallowing. The maximum isometric strength of three moderately affected muscles in each patient (table) was quantified using a myometric technique (Penny and

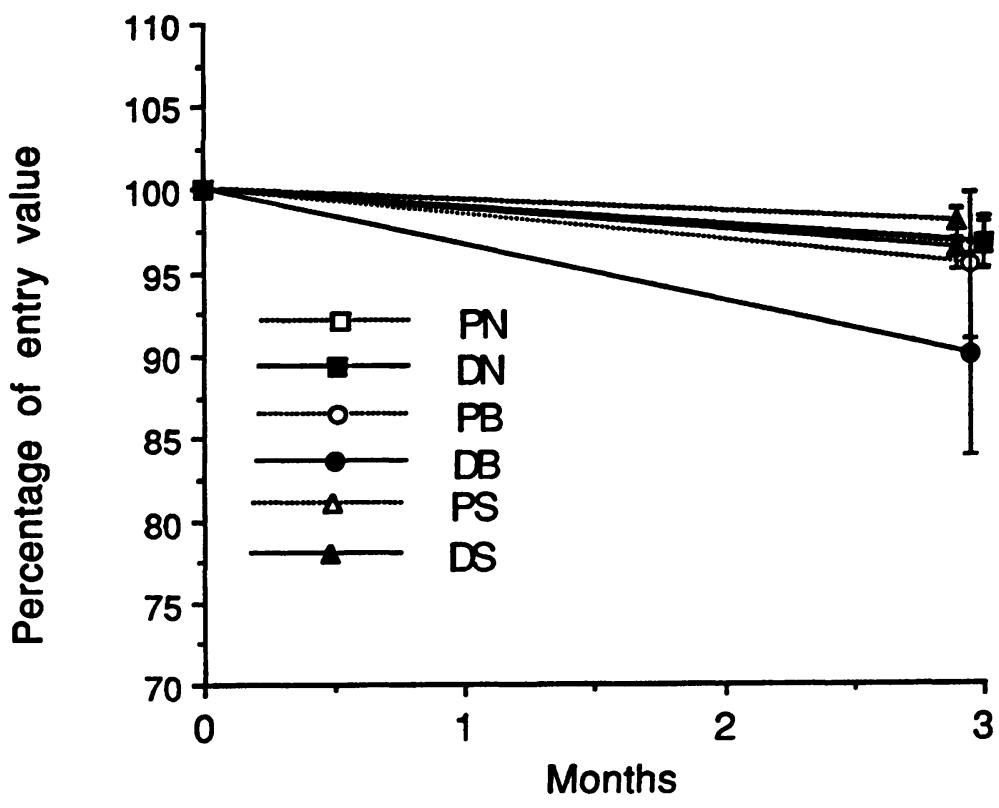

Figure 1 Changes in ALS scores during treatment with dextromethorphan (D) and placebo $(P)$ in the double-blind trial. $N=$ Norris score, $B=$ bulbar score, $S=$ spinal score. Means and standard errors are shown
Gilles Transducers, UK). ${ }^{12}$ The mean of three maximum values of each muscle function was chosen. In the double-blind trial the parameters above were tested immediately before and at the termination of each treatment period (for example, after 12, 16 and 28 weeks). In the following open trial the patients still participating were tested every third month. The test results at the start of each treatment $(0,16$ and 28 weeks) were used as baseline values for the respective treatment period.

\section{Electrophysiological methods}

The effects were assessed using two electrophysiological methods. Firstly, compound muscle action potentials (CMAP), obtained after maximal nerve stimulation, were recorded over the abductor digiti minimi (ADM) muscle using standard silver cup electrodes. Amplitudes were measured peak to peak. Secondly, the number of axons was estimated using our PC based modification of the $\mathrm{McCo}$ mas technique. ${ }^{1314}$ The evoked muscle response from the abductor digiti minimi muscle was recorded using the same electrode montage as for the CMAP recordings. The Ulnar nerve was stimulated with surface electrodes at the wrist, using $0 \cdot 1 \mathrm{~ms}$ square wave pulses of gradually increasing strength. The evoked muscle response increased in steps, each considered to reflect a single motor unit, that is, one axon. The computer subtracted the previous CMAP from the accepted new one, and the shape of the new motor unit action potential was displayed. Up to 20 units were recorded, generating a subtotal M-response. From information about the number of units generating this subtotal response, its area, and the area of the maximal M-response, the total number of axons in the muscle could be estimated.

The amplitude and area of the CMAP reflect the combination of denervation and reinnervation. Force measurements estimate denervation, reinnervation and central drive as a whole.

To compare the results from different patients, we used relative values. The number of axons and amplitudes during the study was calculated relative to the values at the beginning of each treatment period.

\section{Statistical evaluation}

Analysis of variance (ANOVA) for cross over design was used.

\section{Results}

In the double-blind trial all patients $(n=10)$ showed a decrease in spinal scores during medication with both dextromethorphan and placebo. Three patients showed a decrease in bulbar scores during both treatment regimes, while the other patients had stable bulbar scores. Four of the patients exhibited no change in Norris scores while the rest of the patients showed a continuous decrease in these scores. The changes in the mean scores are shown in fig 1 . There were no significant 


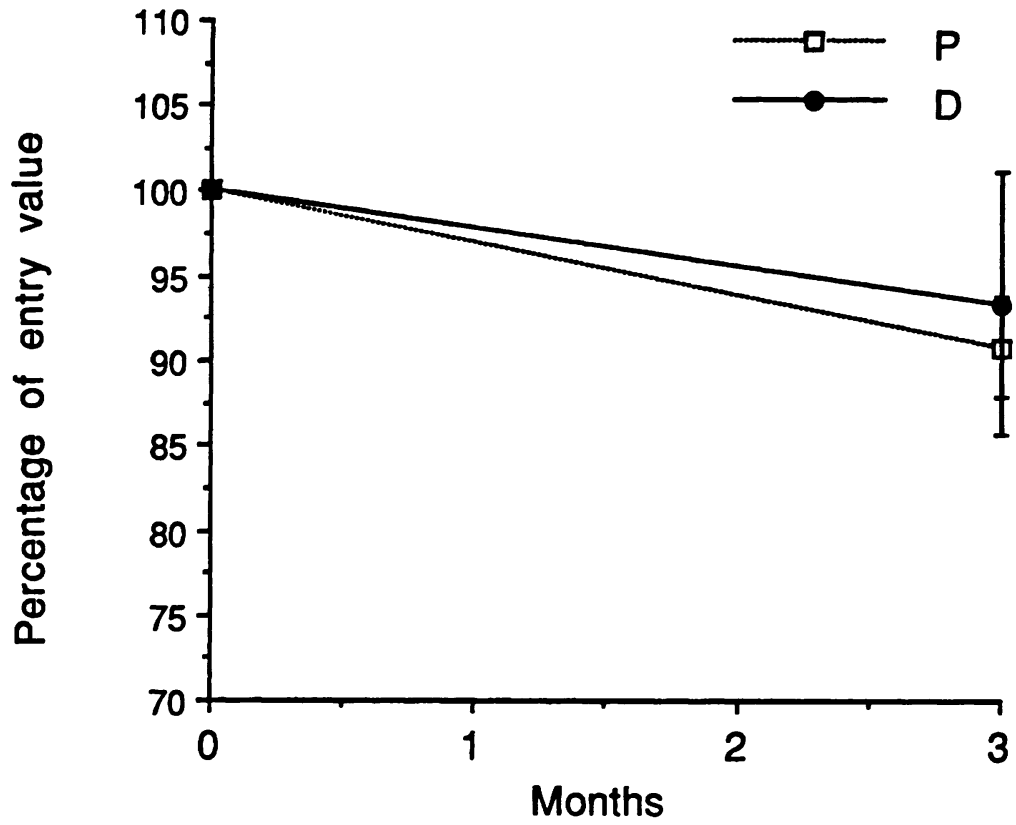

Figure 2 Changes in muscle strength (mean of the patients mean myometric values) during treatment with dextromethorphan (D) and placebo $(P)$ in the double-blind trial. Means and standard errors are shown

differences in the changes in any scores between the two treatment regimes.

In the following open trial the patients still participating ( 3 months $\mathrm{n}=8,6$ months $\mathrm{n}=$ 6 ), showed a decrease in mean (SEM) spinal scores $[4.5(1.2) \%$ at 6 months] while their bulbar scores remained unchanged. All of these patients except one showed a mean (SEM) decrease in Norris scores [6 (2.5)\% at 6 months] during this part of the study.

In the double-blind trial the strength of the tested muscles decreased in all patients (fig 2). There was no significant difference between the decrease during the period of treatment

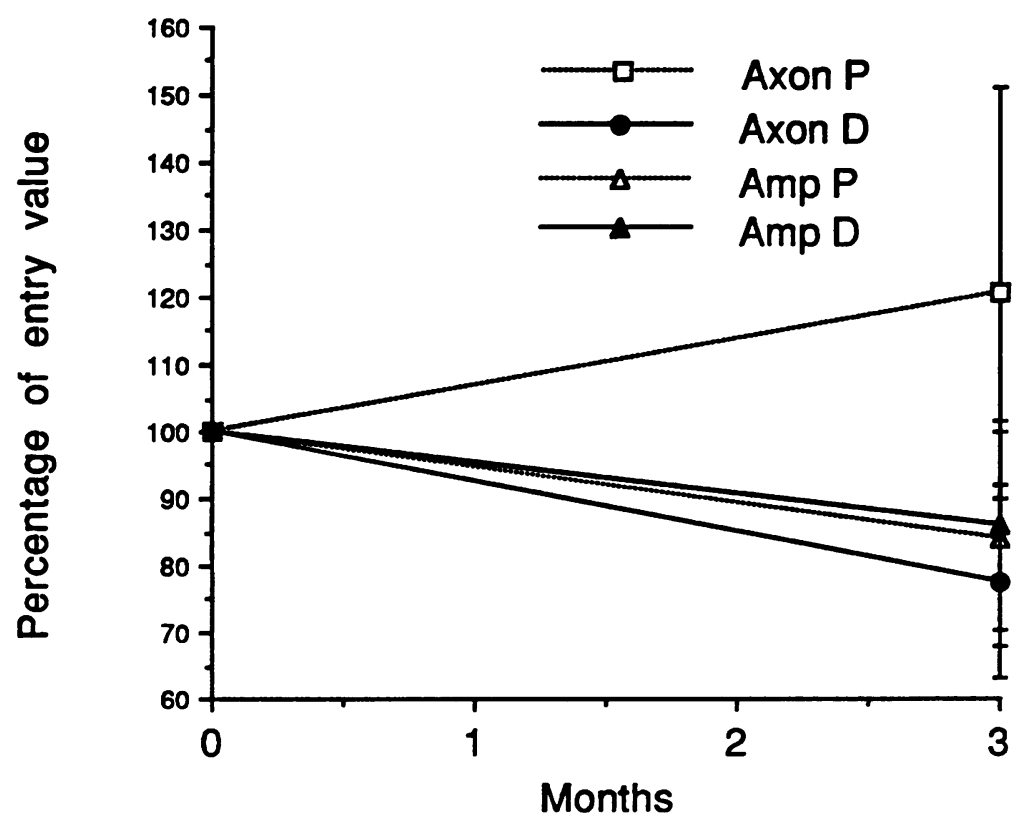

Figure 3 Changes in the relative number of axons ( $A X O N$ ) and in amplitudes of compound muscle action potentials in the abductor digiti minimi muscle (AMP) during treatment with dextromethorphan $(D)$ and placebo $(P)$ in the double-blind trial. Means and standard errors are shown with dextromethorphan and that during the period with placebo. In the following open trial there was no significant change in muscle strength.

In the double-blind trial the relative number of axons, when calculated for the whole material, decreased by $22 \%$ during treatment with dextromethorphan and increased by $21 \%$ during treatment with placebo (fig 3). The relative value of CMAP in the ADM muscle, when calculated on the whole material, decreased by $14 \%$ during treatment with dextromethorphan and by $16 \%$ during treatment with placebo (fig 3 ). There were no significant differences in the changes in the neurophysiological parameters between the two treatment regimes. In the following open trial the relative number of axons decreased by $42 \%$ and the relative value of CMAP in the ADM muscle by $56 \%$ over a 6 month period.

Dextromethorphan was withdrawn in one patient (11) after only three days of medication with $150 \mathrm{mg}$ per day because of pronounced dizziness and nausea. Patient 13 complained of dizziness and constipation after two weeks of medication with $300 \mathrm{mg}$ dextromethorphan per day; the symptoms disappeared after lowering the dose to $150 \mathrm{mg}$ per day. No other side effects were reported.

\section{Discussion}

All neurophysiological parameters deteriorated during the study except during placebo treatment where the relative number of axons showed an increase. This increase, which was not statistically significant, may be explained by the large intraindividual variations in the estimation of the number of axons and other shortcomings. ${ }^{1516} \mathrm{We}$ are aware of those. Estimation of axons has a certain variation even when repeated on the same patient. Two patients were investigated four times over a two day period. They exhibited an axon count range 42-85 (mean 73) and 22-32 (mean 26), respectively. In spite of the methodological shortcomings we still feel that the method may be valuable as the best available method of providing information about the number of functioning motor units. Because of the intraindividual variations, however, 12 weeks may be too short a time period for demonstrating loss of axons. Therefore, these results, although negative, do not categorically exclude effects of the drug.

The treatment period in the double-blind study was rather short, but for ethical reasons we found it difficult to treat these patients for longer than 12 weeks with placebo. However, it is our opinion that a longer treatment period would not have led to a different result, as there were no positive effects in the following open trial. The six patients who completed the open study continued to deteriorate slowly even after the cessation of the study in spite of continuous treatment with $300 \mathrm{mg}$ dextromethorphan daily, and three of them have died during the year of observation after the termination of the study.

One cannot exclude that the given doses 
were too low. However, $300 \mathrm{mg}$ daily, as given in the open study, is twice the highest dose recommended by the manufacturer and at the time of the study we did not consider a higher dose could be given. It cannot be determined whether the dizziness experienced by two of the patients was due to a morphine agonistic or an NMDA-antagonistic effect.

The lack of any obvious effect from dextromethorphan in our study does not necessarily imply that the underlying hypothesis is wrong. The process of degeneration may have proceeded too far and the NMDA receptor antagonistic activity of dextromethorphan in the tested doses may have been too weak. In a pilot study of this type there is also a risk of type II error. However, as there were no positive effects in any of the parameters, we find it unlikely that the drug in the doses given has any beneficial value of clinical importance in the treatment of ALS. Moreover, glutamate neurotoxicity may also be mediated by nonNMDA receptors ${ }^{17} 18$ and such mechanisms might be involved in ALS. ${ }^{19}$ Studies with other NMDA receptor antagonists as well as development of non-NMDA receptor antagonists for therapeutic trials are desirable.

The study was supported by the NHR Foundation, Sweden, and the Swedish Medical Research Council (No 4373). We thank Mrs Gun Kärrlander for excellent secretarial assistance.

1 Plaitakis A, Mandeli J, Smith J, Yahr MD. Pilot trial of branched chain aminoacids in amyotrophic lateral sclerosis. Lancet 1988;1:1015-18.

2 Spencer PS. Guam ALS/parkinsonism-dementia: A longlatency neurotoxic disorder caused by "slow toxin(s)" in food. Can 7 Neurol Sci 1987;14:347-57.

3 Plaitakis A Glutamate dysfunction and selective moto neuron degeneration in amyotrophic lateral sclerosis: A hypothesis. Ann Neurol 1990;28:3-8.

4 Plaitakis A, Caroscio JT. Abnormal glutamate metabolism in ALS. Ann Neurol 1985;18:165.

5 Plaitakis A, Caroscio JY. Abnormal glutamate metabolism in amyotrophic lateral schlerosis. Ann Neurol 1987;22: 575-79.

6 Plaitakis A. Altered glutamatergic mechanisms and selective motor neuron degeneration in amyotrophic lateral sclerosis. Possible role of glycine. In: Rowland LP, ed. Advances of neurology, vol 56, amyotrophic lateral sclerosis and other motor neuron diseases. New York: Raven Press, 1991:319-26.

7 Choi DW. Glutamate neurotoxicity and diseases of the nervous system. Neuron 1988;1:623-34.

8 Wong B, Coulter D, Choi D, Priner D. Dextrorphan and dextromethorphan common antitussives are antiepileptic and antagonize NMDA in brain slices. Soc Neurosci Abstr 1987;13:1560.

9 Aryanpur JJ, Eccles C, Cole AE, Fisher RS. Dextromethorphan and dextrorphan selectively block depolarization by NMDA in rat hippocampal slice. Neurology 1988;38 (Suppl 1):301

10 Criteria for diagnosis of amyotrophic lateral sclerosis. World Neurology 1990;15:12.

11 Norris FH, Calanchini PR, Fallat RJ, Panchart RPT, Jewett $B$. The administration of guanidine in amyotrophic lateral sclerosis. Neurology 1974;24:721-8.

12 Scott OM, Goiddard C, Dubowitz V. Quantitation of muscle function in children: a prospective study in Duchenne muscular dystrophy. Muscle Nerve 1982;5: 291-301.

13 McComas AJ, Fawcett PRW, Campbell MJ, Sica REP. Electrophysiological estimation of the number of motor units within a human muscle. $\mathcal{f}$ Neurol Neurosurg Psyunits within a human mus
chiatry $1971 ; 34: 121-31$.

14 Ballantyne JP, Hansen S. A new method for the estimation of the number of motor units in a muscle. $\mathcal{f}$ Neurol of the number of motor units in a
Neurosurg Psychiatry 1974;37:907-15.

15 Slawnych MP, Laszlo CA, Hershler C. A review of techniques employed to estimate the number of motor units in a muscle. Muscle Nerve 1990;13:1050-64.

16 Stein RB, Yang JF. Methods for estimating the number of motor units in human muscles. Ann Neurol 1990;28:487-95.

17 Koh J, Hartley DM, Choi DW. Non-NMDA receptor mediated neurotoxicity in cortical cultures. Soc Neurosci Abstr 1988;14:746.

18 Koh J, Goldberg MP, Hartley DM, Choi DW. Non-NMDA receptor mediated neurotoxicity in cortical culture. $\mathcal{F}$ Neurosci 1990;10:693-705.

19 Weiss JH, Choi DW. Slow non-NMDA receptor mediated neurotoxicity and amyotrophic lateral sclerosis. In: Rowland LP, ed. Advances of neurology, vol 56, amyotrophic lateral sclerosis and other motor neuron diseases. New York:
late lateral sclerosis and other mo
Raven Press, 1991:311-18. 